\title{
Evidences of interdependence and contagion using a frequency domain framework
}

Citation for published version (APA):

Bodart, V., \& Candelon, B. (2005). Evidences of interdependence and contagion using a frequency domain framework. METEOR, Maastricht University School of Business and Economics. METEOR Research Memorandum No. 023 https://doi.org/10.26481/umamet.2005023

Document status and date:

Published: 01/01/2005

DOI:

10.26481/umamet.2005023

Document Version:

Publisher's PDF, also known as Version of record

\section{Please check the document version of this publication:}

- A submitted manuscript is the version of the article upon submission and before peer-review. There can be important differences between the submitted version and the official published version of record.

People interested in the research are advised to contact the author for the final version of the publication, or visit the DOI to the publisher's website.

- The final author version and the galley proof are versions of the publication after peer review.

- The final published version features the final layout of the paper including the volume, issue and page numbers.

Link to publication

\footnotetext{
General rights rights.

- You may freely distribute the URL identifying the publication in the public portal. please follow below link for the End User Agreement:

www.umlib.nl/taverne-license

Take down policy

If you believe that this document breaches copyright please contact us at:

repository@maastrichtuniversity.nl

providing details and we will investigate your claim.
}

Copyright and moral rights for the publications made accessible in the public portal are retained by the authors and/or other copyright owners and it is a condition of accessing publications that users recognise and abide by the legal requirements associated with these

- Users may download and print one copy of any publication from the public portal for the purpose of private study or research.

- You may not further distribute the material or use it for any profit-making activity or commercial gain

If the publication is distributed under the terms of Article $25 \mathrm{fa}$ of the Dutch Copyright Act, indicated by the "Taverne" license above, 


\title{
Evidences of Interdependence and Contagion using a Frequency Domain Framework \\ by
}

\author{
Vincent Bodart ${ }^{1}$ and Bertrand Candelon ${ }^{2}$
}

\begin{abstract}
The purpose of this paper is to propose a new measure of contagion. Our approach to testing contagion is based on the frequency analysis of causality developed recently by Breitung and Candelon (2004). This approach handles, in a unified framework, several of the statistical problems identified in the literature. It also permits clear differentiation between temporary and permanent shifts in cross-market linkages: the first case is contagion while the second one is simply a measure of interdependence among markets. In examining the "Tequila" and Asian crises, we find evidence for contagion during both. It also turns out that during the Asian crisis both contagion and higher interdependence have contributed simultaneously to the diffusion of the crisis in Asia. The spillover effects of these crises have been geographically limited to the region where the shock originated.
\end{abstract}

Keywords: Contagion, Financial crisis, Causality Test, Frequency domain.

\footnotetext{
${ }^{1}$ Department of Economics and IRES, Universite Catholique de Louvain, 3 place Montesquieu, 1348 Louvain-la-Neuve, Belgium

${ }^{2}$ Corresponding Author: Bertrand Candelon, Department of Economics, Maastricht University, PoBOX 616, MD 6200, Maastricht, The Netherlands, Email: b.candelon@algec.unimaas.nl, Tel; +31433 883 442, Fax:+31433 884864
} 


\section{Introduction}

The international financial crises of the last decade have shown that financial shocks in one country can have rapid and large impacts in other countries. In recent years, numerous papers have examined the issue of whether contagion was responsible for this strong linkage among markets during periods of crisis. Measuring financial contagion however poses several problems.

One problem is that economists disagree on what contagion exactly is. The concept of contagion is inherited from the medical vocabulary and indicates the transmission of a contagious disease. The translation to an economic concept is not straightforward, as illustrate the numerous definitions of contagion that can be found on the World Bank's website. Several authors, among others Rigobon (1999) and Forbes and Rigobon (2002), define contagion as a significant and temporary increase in cross-market linkages after a shock. Contagion can take place both across markets, for instance between the foreign exchange market and the stock market, and across countries. This concept of contagion is often labelled "shift-contagion". Shift-contagion can be generated by multiple equilibria based on investor psychology, endogenous-liquidity shocks causing a portfolio reshuffling and political economy affecting exchange rate regimes (see Rigobon (2000) for a survey). For other authors, contagion is simply the cross-country or cross-market transmission of shocks, no matter whether the linkages are reinforced or not. These authors are generally concerned with the identification of the channels through which shocks are transmitted. The most important channels are the trade channel (Glick and Rose, 1998), the financial channel (van Rickenghem and Weder, 2001), similarities between economies (Eichengreen, Rose and Wyplosz, 1996), policy coordination 
or the geographical proximity (Bayoumi and alii, 2003). In the literature, this approach of contagion is often referred to as "pure" or "fundamental based" contagion.

The remainder of this study will focus solely on the aforementioned "shift-contagion". The term "contagion" is therefore used to describe a temporary and significant shift in cross-market linkages. It may occur that the shift in cross-market linkages after a shock is permanent rather than temporary. This paper will refer to this situation as a change in "market interdependence". Therefore the terms 'contagion " and "interdependence" describe two markedly different phenomena.

Measuring financial contagion also poses several statistical problems, as shown for instance by Forbes and Rigobon $(1999,2001)$ in several papers. A variety of econometric techniques have been used to measure contagion. An intuitive, and widely used, technique has been to test whether the correlation between two markets was significantly higher during the period following the crisis compared to the period preceding the crisis. For example, King and Wadhwani (1990) show that the cross-market correlation between the U.S., U.K and Japan has significantly increased after the U.S. stock market crash in 1987. Calvo and Reinhart (1995), Baig and Goldfajn (1998) use a similar approach to show the presence of shift-contagion after the 1994 Mexican peso crisis and the 1997 Asian crisis. Nevertheless, this intuitive approach presents several shortcomings. First, correlation is a static and bivariate measure. It thus neglects the possible dynamic structure of the linkages and may in addition omit contributing variables. For example, if a shock in the Russian equity market is transmitted to the Mexican exchange market via the Brazilian exchange market, the correlation will not detect contagion. Secondly, correlation automatically increases during period of high 
volatility (e.g. when the process exhibits heteroscedasticity or conditional heteroscedasticity) and during periods of globalization (e.g. when there is a stochastic trend). Hence, a significant shift in the correlation coefficient after a crisis may have nothing to do with contagion. Thus, statistical procedures used in practice to test for the stability of the correlation have to be robust to the presence of heteroscedasticity and trend (which corresponds to a common trend in each series). Thirdly, correlation is a symmetrical measure: an increase in the correlation between markets i and $\mathrm{j}$ does not give any information on the direction of the contagion (from $\mathrm{i}$ to $\mathrm{j}$, from $\mathrm{j}$ to $\mathrm{i}$, or both). Contagion, in fact, has a clearly asymmetric dimension. It is for these reasons that several other approaches have been used to measure cross-market linkages: Rigobon (2002) and Corsetti et alii (2001) use a principal component model and build a test robust to heteroscedasticity. Candelon and alii (2004) use the concept of common feature, which takes into account the dynamic nature of correlation and thus minimizes the effect of possible omitted variables.

In this paper, we present a new approach to measure shift-contagion. The innovation consists of using causality tests in the frequency domain to detect whether the strength of asset market linkages is altered by a financial crisis. We assert that this new approach offers a more suitable way to measure shift-contagion. Indeed, the focus on the causal structure rather than on static correlation allows one to both take into account the underlying dynamic structure, and deal with the problem of asymmetry. In addition, the frequency domain allows us to test for causality at each frequency (see Geweke, 1982, Hosoya and Yao, 1998 and Breitung and Candelon, 2004) and thus offers a simple way to discriminate between contagion and interdependence. By comparison, 
time domain causality tests are performed for the whole range of frequencies and so ignore the possible differences between short-run (concerning high frequencies) and long-run (low frequencies) causality.

The rest of the paper is organized as follows. Section 2 presents the key features of our measure of contagion. In section 3, we describe the methodology and the econometric framework. A simulation analysis is performed to analyze the robustness of the causality test in the frequency domain with respect to changes in volatility. In section 4, we use our approach to test for the existence of contagion among several stock markets in Latin America and in Asia during the financial crises of 1994 and 1997.

\section{A new approach of contagion}

Shift-contagion has been defined as a significant and temporary increase in cross-market linkages after a shock in a "ground-zero" market. From this definition, one can identify three important

features of contagion: (i) Cross-market linkages should increase after the shock; (ii) The shock is transmitted from one country to a different one; (iii) The diffusion of the shock is temporary.

Regarding (i), a simple and common way of testing for shift-contagion is to test if the contemporaneous correlation coefficient between asset returns in different countries has significantly increased before and after the crisis (Rigobon, 2002). This approach does not, however, satisfy (ii) as correlation is by nature a symmetrical measure: an increase in the correlation between markets $\mathrm{i}$ and $\mathrm{j}$ does not give any information on the origin of the shock or on the direction of its propa- 
gation (from $\mathrm{i}$ to $\mathrm{j}$, from $\mathrm{j}$ to $\mathrm{i}$, or both). To take asymmetry into account, we propose a test of contagion that is based on causality measures rather than on contemporaneous correlation coefficients. The literature already provides a few attempts in this direction (Favero and Giavazzi, 2002 and Rigobon, 2000) and several concepts of causality exist (see the special issues of the Journal of Econometrics, 1988 and 2004). We consider here Granger-causality, not so much because it is popular and easy to implement, but mainly because it has the advantage of modeling asymmetry explicitly. With regard to the objective of measuring cross-market linkages, another advantage of using causality rather than correlation comes from the fact that causality is actually correlation conditional on the dynamic structure of the system. The omitted variable problem, encountered in papers using contemporaneous correlation coefficient, is therefore avoided.

Compared to (i) and (ii), feature (iii) has received less attention in the literature. To illustrate its importance, assume that $x_{i}$ and $x_{j}$ are two asset returns in countries $\mathrm{i}$ and $\mathrm{j}$, each return being composed of a permanent or long-run term $(\bar{x})$ and a transitory or short-run term $(\hat{x})$. Stronger linkages between the two returns could be due either to a higher co-movement between the permanent components of the returns, or to a higher co-movement between their short-run components. There will be contagion only in the latter case; contagion is therefore measured by a stronger linkage among the short-run components of the two returns after a crisis. In the former case, as the shift in cross-market linkages is permanent, what is measured is not shift-contagion but a higher integration of markets. Simply computing correlations, even causality measures, without distinguishing short- and long-run components will therefore only provide spurious measures of contagion. ${ }^{3} \mathrm{~A}$

\footnotetext{
${ }^{3}$ To draw a comparison with business cycle analysis, the real interdependence among two countries may increase
} 
simple way to handle this distinction is to tackle the problem in a frequency domain framework. Indeed, each frequency corresponds to a particular component of the variable: components at low frequencies are more persistent than components at high frequencies. In particular, frequency 0 corresponds to a permanent component. Thanks to this frequency discrimination, we can isolate whether the increase in cross-market linkages is due to long-run (low frequency) or short-run (high frequency) components. Only the latter case corresponds to contagion.

In order to integrate features (i), (ii) and (iii) into a single statistical test, we propose to measure contagion using causality tests in the frequency domain. According to this approach, contagion is present if there is a significant increase in the causality at high frequencies. Figures 1 and 2 illustrate this point. On each graph, the statistics of the causality test for frequencies between $[0, \pi]$ are plotted for the period preceding (thick line) and following (thin line) the shock. The horizontal line corresponds to the critical value of the test. ${ }^{4}$ In figure 1, causality significantly increases at low frequencies after the shock, whereas in figure 2 the increase in causality occurs at high frequencies. The case depicted in figure 2 corresponds to contagion, while figure 1 illustrates higher interdependence. In utilizing our approach, contagion and interdependence can be analyzed in a unified framework, and so they can be distinguished very easily. Figures 1 and 2 illustrate another advantage of testing for contagion in the frequency domain rather than in the time domain. In the time domain, causality tests are computed for the whole range of frequencies. Because of this, tests in the time domain will very likely reject the causality in both cases as the range of because of an increase in the interdependence of their seasonal components (short-run causality) or their cycle components (longer-run causality).

${ }^{4} \mathrm{~A}$ description of the test is provided in the next section. 
frequencies for which causality is accepted is relatively small compared to $[0, \pi]$. In the time domain, contagion will thus be rejected, even if it is present in figure 2 . The causality test in the frequency domain would, however, have detected the existence of shift-contagion.

Include Figures 1 to 2 about here

\section{Methodology}

\subsection{Causality in the frequency domain: A test}

Our new approach to contagion relies on the causality test in the frequency domain recently developed by Breitung and Candelon (2004). The usual definition of causality is due to Granger (1969) and is based on the forecast variance. To illustrate this, let us consider $z_{t}=\left[x_{t}, y_{t}\right]^{\prime}$ to be a two-dimensional vector of time series observed at $t=1, \ldots, T$. In our application, $x_{t}$ and $y_{t}$ will be equity returns in two different countries, where one of the two countries being the "ground-zero" country where the crisis started. It is assumed that $z_{t}$ has a finite order vector autoregressive (VAR) representation of the form:

$$
\Theta(L) z_{t}=\varepsilon_{t}
$$

where $\Theta(L)=I-\Theta_{1} L-\cdots-\Theta_{p} L^{p}$ is a $2 \times 2$ lag polynomial with $L^{k} z_{t}=z_{t-k}$. We assume that the error vector $\varepsilon_{t}$ is white noise, with $E\left(\varepsilon_{t}\right)=0$ and $E\left(\varepsilon_{t} \varepsilon_{t}^{\prime}\right)=\Sigma$, where $\Sigma$ is positive definite. For ease of exposition, we do not include any deterministic terms in (1) although in empirical applications the model typically includes a constant. Here, $y_{t}$ is Granger causal for $x_{t}$ if the forecast variance 
of $x_{t+1}$ conditional on $\mathcal{X}_{t}=\left\{x_{t}, x_{t-1}, \ldots\right\}$ is larger than forecast variance of $x_{t+1}$ conditional on $\mathcal{X}_{t} \cup \mathcal{Y}_{t}$, where $\mathcal{Y}_{t}=\left\{y_{t}, y_{t-1}, \ldots\right\}$. In other words $\mathcal{Y}_{t}$ contains information to predict the one-step ahead value of $x_{t}$.

The extension of this framework in the frequency domain has been proposed by Geweke (1982) and Hosoya (1991). Let $G$ be the lower triangular matrix of the Cholesky decomposition $G^{\prime} G=$ $\Sigma^{-1}$ such that $E\left(\eta_{t} \eta_{t}^{\prime}\right)=I$ and $\eta_{t}=G \varepsilon_{t}$. If system (1) is assumed to be stationary, the MA representation of the system is

$$
\begin{aligned}
z_{t} & =\Phi(L) \varepsilon_{t}=\left[\begin{array}{ll}
\Phi_{11}(L) & \Phi_{12}(L) \\
\Phi_{21}(L) & \Phi_{22}(L)
\end{array}\right]\left[\begin{array}{l}
\varepsilon_{1 t} \\
\varepsilon_{2 t}
\end{array}\right] \\
& =\Psi(L) \eta_{t}=\left[\begin{array}{ll}
\Psi_{11}(L) & \Psi_{12}(L) \\
\Psi_{21}(L) & \Psi_{22}(L)
\end{array}\right]\left[\begin{array}{l}
\eta_{1 t} \\
\eta_{2 t}
\end{array}\right]
\end{aligned}
$$

where $\Phi(L)=\Theta(L)^{-1}$ and $\Psi(L)=\Phi(L) G^{-1}$.

The measure of causality suggested by Geweke (1982) and Hosoya (1991) is the following:

$$
M_{y \rightarrow x}(\omega)=\log \left[1+\frac{\left|\Psi_{12}\left(e^{-i \omega}\right)\right|^{2}}{\left|\Psi_{11}\left(e^{-i \omega}\right)\right|^{2}}\right] .
$$

Several methods have been proposed to test for the nullity of $\left|\Psi_{12}\left(e^{-i \omega}\right)\right|=0$, corresponding to the case where $y$ does not cause $x$ at frequency $\omega$.

Breitung and Candelon (2004) propose the simplest approach to test for the null hypothesis of non-causality (i.e. $M_{y \rightarrow x}(\omega)=0$ ) based on the necessary condition $\left|\Psi_{12}\left(e^{-i \omega}\right)\right|=0$, using $\Psi(L)=\Theta(L)^{-1} G^{-1}$ and

$$
\Psi_{12}(L)=-\frac{g^{22} \Theta_{12}(L)}{|\Theta(L)|}
$$

where $g^{22}$ is the lower diagonal element of $G^{-1}$ and $|\Theta(L)|$ is the determinant of $\Theta(L)$. It follows 
that $y$ does not cause $x$ at frequency $\omega$ if ${ }^{5}$

$$
\left|\Theta_{12}\left(e^{-i \omega}\right)\right|=\left|\sum_{k=1}^{p} \theta_{12, k} \cos (k \omega)-\sum_{k=1}^{p} \theta_{12, k} \sin (k \omega) i\right|=0 \text {. }
$$

Their empirical procedure consists of testing for these linear restrictions. To simplify the notation, we let $\alpha_{j}=\theta_{11, j}$ and $\beta_{j}=\theta_{12, j}$, so that the VAR equation for $x_{t}$ is written as

$$
x_{t}=\alpha_{1} x_{t-1}+\cdots+\alpha_{p} x_{t-p}+\beta_{1} y_{t-1}+\cdots+\beta_{p} y_{t-p}+\varepsilon_{1 t} .
$$

The hypothesis $M_{y \rightarrow x}(\omega)=0$ is equivalent to the linear restriction

$$
H_{0}: \quad R(\omega) \beta=0,
$$

where $\beta=\left[\beta_{1}, \ldots, \beta_{p}\right]^{\prime}$ and

$$
R(\omega)=\left[\begin{array}{cccc}
\cos (\omega) & \cos (2 \omega) & \cdots & \cos (p \omega) \\
\sin (\omega) & \sin (2 \omega) & \cdots & \sin (p \omega)
\end{array}\right]
$$

This restriction tests that $(5)$ is an ordinary $F$ statistic and is asymptotically distributed as $F(2, T-$ $2 p)$ for $\omega \in(0, \pi)$. Such a method can be extended to higher dimensional systems or to cointegrated VARs (see Breitung and Candelon, 2004). The comparison with the causality test in time domain is not straightforward. It is very difficult to find correspondence between the procedures, which test for k-ahead causality (Dufour and Renault, 1998, 2003). This procedure determines if a particular component (characterized by the frequency $\omega$ ) of one series causes the component at the same frequency of the variable of interest one period ahead. Such a definition fits to the concept of contagion, presented in section 2. The k-ahead causality appears to be inappropriate in such a

\footnotetext{
${ }^{5}$ Note that $g^{22}$ is positive due to the assumption that $\Sigma$ is positive definite.
} 
case as it does not distinguish the linkages between the short- and the long-run components of the series.

\subsection{Simulation study}

To investigate the finite sample properties of the aforementioned tests in the presence of misspecifications (outliers and heteroscedasticity) often encountered when using financial data, we generate the same stationary model as in Breitung and Candelon (2004):

$$
\begin{aligned}
& x_{t}=0.1 x_{t-1}+0.3 b_{\omega}(L) y_{t-1}+\varepsilon_{1 t} \\
& y_{t}=-x_{t-1}+0.1 y_{t-1}-0.2 y_{t-2}+0.3 y_{t-3}+\varepsilon_{2 t},
\end{aligned}
$$

where

$$
\varepsilon_{t} \sim N(0, \Sigma), \quad \Sigma=\left[\begin{array}{ll}
0.5 & 0.2 \\
0.2 & 0.5
\end{array}\right]
$$

and $b_{\omega}(L)=1-2 \cos (\omega) L+L^{2}$. At frequency $\omega$ the gain function of the polynomial is zero and therefore $y$ is not a cause of $x$ at this particular frequency. To investigate the consequences of misspecification for the causality test, we consider two types of problems often encountered in the contagion literature. First, the presence of outliers, representing the crisis itself, might affect the causality test. Lütkepohl (1989) has demonstrated via simulation study that the performance of the Granger-causality test in the time domain is affected by the presence of structural breaks. Two cases are scrutinized here. In the first experiment, we allow for the presence of one outlier in the middle of the sample. The size of the outlier corresponds to 20 times the variance of 
the process and thus represents an excessive shock ${ }^{6}$. Then, we introduce two outliers of similar magnitude located towards the first and the last quarter of the sample. Secondly, we investigate the performance of our test in the presence of conditional heteroscedasticity. Under conditional heteroscedasticity, OLS estimators are still convergent but loose their efficiency, leading to size distortions for specification tests. As noticed by Rigobon (2000), heteroscedasticity is observable in financial series and leads to the over-acceptance of contagion. The aim of the simulation is to see how much conditional heteroscedasticity affects the causality test in the frequency domain. If so, an adequate correction (i.e. a White heteroscedastic consistent variance-covariance matrix) has to be employed). In the simulation, we consider conditional heteroscedasticity via a multivariate constant conditional correlation GARCH (ccc-GARCH) a la Bollerslev (1990) such that:

$$
h_{i, t}=\omega i+\alpha_{i} \epsilon_{i, t-1}^{2}+\beta_{i} h_{i, t-1} \quad i=1,2,
$$

and $H_{t}=D_{t} C H_{t}$, where $D_{t}=\operatorname{diag}\left(\sqrt{h}_{i t}\right)$ and $C=\left(\begin{array}{cc}1 & 0.5 \\ 0.5 & 1\end{array}\right)$.

The residuals are generated according to $\epsilon_{t}=u_{t} \bar{H}_{t}$, where $\epsilon_{t}=\left(\epsilon_{1 t}, \epsilon_{2 t}\right)^{\prime}$ and $u_{i t}$ are independent $N(0,1)$, and $\bar{H}_{t}$ comes from the Cholesky decomposition $H_{t}=\bar{H}_{t} \bar{H}_{t}^{\prime}$. We consider a parametrization $(0.01,0.2,0.79)$ such that the unconditional variance equals one and thus is identical to the model without GARCH. The coefficients represent the models encountered in practice, i.e. with a steep news impact curves.

For the Monte Carlo experiments, we compute the rejection frequencies based on 5,000 replica-

\footnotetext{
${ }^{6}$ We consider such a large outlier to give the maximum penalty at the size of the causality test.
} 
tions of the process with sample sizes $T=500$ and $T=1,000$, and consider the 0.05 significance level. Table 1 indicates the results obtained.

Include Table 1 about here

It turns out that the size of the test is not affected by the presence of a large outlier (20 times the variance of the process). Even if the rejection frequency is below the nominal size, it remains close to the $5 \%$ boundary. This undersized problem is more acute when introducing the two other outliers. Then, the rejection frequency dramatically decreases. It is noticeable that the rejection frequencies at high frequency $(\omega=\pi / 4)$ do not depart too much from the $5 \%$ boundary contrary to what it is observed at higher frequencies. It indicates nevertheless that the problem of outliers has to be tackled before performing the causality analysis. The presence of ccc-GARCH is also investigated. It turns out that, contrary to the previous case, the rejection frequency is higher than the nominal size and lies around $6 \%$. The test is thus slightly oversized in the presence of cccGARCH. In figure 3, the empirical power of the causality test in the frequency domain in presence of ccc-GARCH is analysed, by simulating 5,000 times the previous bivariate VAR with i.i.d. white noise residuals as well as with ccc-GARCH. We consider a sample size of 500 observations for two particular frequencies $(\pi / 2$ and $\pi / 4)$. It turns out that in presence of ccc-GARCH, the empirical power has the same shape as in the presence of i.i.d. white noise residuals. A leakage problem, as well as a decrease in the power for frequencies close to 0 , are observed. We nevertheless notice that the power of the causality test is always lower in presence of ccc-GARCH. The size and 
power analysis show that the causality test in the frequency domain can be used in the presence of ccc-GARCH, but not in presence of large structural breaks.

Include Figure 3 about here

\section{Empirical Analysis}

The approach developed in the two previous sections is here used to test whether contagion occurred during two famous periods of international financial crisis, the Mexican "Tequila" crisis of 1994 and the Asian "flu" crisis of 1997.

Contagion is examined at the stock market level. We use daily equity data for a sample of eleven emerging countries from Asia and Latin America. The Asian sample includes Hong Kong, Indonesia, Malaysia, the Philippines, South Korea, Taiwan and Thailand; the Latin American sample consists of Argentina, Brazil, Chile, Mexico, and Venezuela, which are the largest economies in the region. ${ }^{7}$ All the data are retrieved from Datastream. Datastream stock market indices are all expressed in US dollars, which is usual practice in many studies (see for instance Forbes and Rigobon (2000), Bekaert and al. (2003), Bae and al. (2000)). ${ }^{8}$ Equity market returns are computed through log-differentiation.

For our empirical investigation, we follow Forbes and Rigobon (2001) and calculate two-day

\footnotetext{
${ }^{7}$ This choice of emerging countries is usual in studies concerned with recent episodes of financial contagion. See for instance Bekaert, Harvey and Ng (2003), Forbes and Rigobon (2000) and Kaminsky and Reinhart (2001).

${ }^{8}$ In some papers, stock market indices are measured in local currency instead of dollars. Bae and al. (2000) and Forbes and Rigobon (2000) find that the choice of the currency denomination does not tend to significantly alter their results.
} 
rolling over returns $\left(R_{2, t}\right)$ in order to account for differences in time zones and official holidays among the different countries in the sample. The proper application of our methodology necessitates the elimination of outliers. To detect outliers, we use the Median Absolute Deviation (MAD) procedure, which is a simple and standard approach. ${ }^{9}$ According to this procedure, an observation is classified as an outlier if :

$$
R_{2, t}>\gamma \beta \operatorname{med}\left(\left|R_{2, t}-\operatorname{med}\left(R_{2, t}\right)\right|\right)
$$

where med is the median operator, $\beta$ is a constant equal to $\left(1 / q_{0.75}\right)$ where $q_{0.75}$ is the 75 th fractile of the sample distribution of $R_{2, t}$. The parameter $\gamma$ is fixed arbitrarily, but a value of 2 or 3 is commonly used in practice. In this paper, $\gamma$ is set equal to 3 .

Each outlier is then replaced by a 10-day average centered around the abnormal observation using:

$$
R_{10 x, t}=(1 / 9) \sum_{i=-4,+4} R_{2 x, t}
$$

Our empirical work uses bivariate models (as in (1)) composed of the return in the country that is considered to be the source of the crisis (the "ground-zero" country) and the return in another country, either in Latin America or in Asia. Contagion can therefore occur between countries in a similar or different geographical regions.

For the Tequila crisis of 1994, as the crisis was triggered by the devaluation of the Mexican peso

\footnotetext{
${ }^{9}$ For a more detailed description of the procedure, see Hotta and Tsay (1988).
} 
in December $19^{t h}$, 1994, the "ground-zero" country is undoubtedly Mexico. Regarding the East Asian crisis, the choice of the country where the crisis originated is not so obvious: in some papers, it is considered that the crisis started with the Thai Baht devaluation on July 2, 1997 while other papers consider that the crisis was triggered by the sharp decline in the Hong Kong stock market in mid-October 1997. In this paper, we consider separately both countries as the "ground-zero" country.

We estimate each model over a pre- and a post-crisis periods. In order to make our results comparable with those from earlier studies, we take the chronology of the crises from previous studies, more precisely from Forbes and Rigobon (2002). Following Forbes and Rigobon (2002), we fix the Tequila crisis as lasting from December $16^{t h}, 1994$ (when the exchange rate regime was abandoned) to January $2^{\text {nd }}$, 1995. Regarding the Asian crisis, taking Hong-Kong as the "groundzero" country, the crisis period goes from October $16^{\text {th }}, 1997$ (when the Hong-Kong stock market crashed) through November $3^{r d}, 1997$; alternatively, when we take Thailand as the origin of the crisis, the crisis period goes from July $2^{\text {nd }}, 1997$ (when the Thai Baht is devaluated) through July $28^{\text {th }}, 1997$ (when Thailand calls the IMF). In line with Forbes and Rigobon (2002), we fix the beginning of the period preceding the crisis on January $1^{\text {st }}, 1993$ for the Mexican Peso crisis, and on January $1^{\text {st }}, 1996$ for the Asian crisis, no matter whether the "ground-zero" country is Hong-Kong or Thailand. Finally, we define the period following the crisis as starting on the last day of the crisis period through the end of the year following the crisis. Precisely, the estimation periods are the following ones: (i) Tequila crisis: pre-crisis $=1 / 01 / 1993$ to $16 / 12 / 1994$; post-crisis 
$=2 / 01 / 1995$ to 29/12/1995; (ii) Asian crisis (Hong-Kong = "ground zero" country): pre-crisis $=1 / 01 / 1996$ to $16 / 10 / 1997$; post-crisis $=03 / 11 / 1997$ to $31 / 12 / 1998$; (iii) Asian crisis (Thailand $=$ "ground zero" country): pre-crisis $=1 / 01 / 1996$ to $02 / 07 / 1997 ;$ post-crisis $=28 / 07 / 1997$ to $31 / 12 / 1998$

In table 2, we report the optimal lag length of each bivariate system for the different sub-periods, having used the AIC information criteria. It is well known that this information criterion slightly overestimates the optimal lag length. By taking the highest dimension of the dynamic structure, we build a conservative causality test, rejecting as often as possible the causality hypothesis as well as the contagion one.

\section{Include Table 2 about here}

Our results are presented in Figures 4 to 9 . On each figure, the statistics of the causality test $(M(\omega))$ as well as the $95 \%$-critical value are plotted for each frequency $(\omega)$. The dotted line corresponds to the statistics for the post-crisis period, whereas the full line indicates the results obtained for the pre-crisis period. As explained before, there is evidence of shift-contagion if the causality is not rejected at high frequencies for the post-crisis period, whereas it is rejected for the pre-crisis period. We restrict the high frequencies to components having a periodicity of two to three days (i.e. $\omega \in[2 \pi / 3, \pi]) .{ }^{10}$ This definition is somewhat ad-hoc, but it is acknowledged that the transmission of shocks among one equity markets is very fast (it can spread from one equity

\footnotetext{
${ }^{10}$ The correspondence between the component periodicity $(c p)$ and the frequency $(\omega)$ is obtained via $\frac{2 \pi}{\omega}=c p$.
} 
market to the other equity markets during the same day) and generally does not exceed half a week. For instance, using impulse response analysis, Baig and Goldfjan (1988) find that during the Asian crisis, the impact on neighboring markets of shocks originating from Thailand's stock market disappeared after about 4 days. Latin American countries' results are reported in figures 4 to 6 , whilst Asian ones are plotted in figures 7 to 9 . For each system, we eliminated outliers using the MAD algorithm. ${ }^{11}$ We can then assume that the residuals are free from autocorrelation and outliers, and thus that the models are correctly specified.

\section{Contagion in Latin America}

Evidence for contagion after the Mexican crisis is found in three countries, namely Argentina, Brazil and Chile (figure 4). For these countries, there is at least one range of frequencies within the high frequencies window defined above (For Chili $\omega \in[2.2,2.8]$, for Brazil $\omega \in[2,2.8]$ and for Argentina $\omega \in[2,2.2])$, at which causality is not rejected for the post-crisis period, whereas it is rejected for the pre-crisis period. This indicates that the linkages between these countries and Mexico did indeed increased after the Tequila crisis, supporting the idea of "shift-contagion". In the case of Venezuela, causality at any frequency is rejected for the post-crisis period, which suggests that the country was not contagiously affected by the Tequila crisis. Our results partly differ from those reported by Forbes and Rigobon (2002): while these authors conclude that there has been no shift-contagion in Latin America during the Tequila crisis, we find that there has been shift-contagion from Mexico to at least three Latin American countries. Such a difference

\footnotetext{
${ }^{11}$ Results are available from the authors upon request.
} 
is a result of our methodology. It appears from figure 4 that our analysis, performed in the time domain (i.e. for the whole range of frequencies), would have matched Forbes and Rigobon (2002)'s conclusions. It is also worth noting that long-run interdependence between Mexico and the other Latin American countries, as measured by causality in the neighborhood of frequency $(\omega=0)$, has not increased after the crisis. Instead, we observe that when there was interdependence before the crisis, it has disappeared after the crisis (see Argentina and Venezuela).

Figures 5 and 6 indicate that the Asian crisis had only minor spillover effect in Latin America, whichever the selected "ground-zero" country. We can only detect support for contagion in Chile, if Thailand is considered the origin of the Asian crisis, and in Argentina, if Hong-Kong is the "ground-zero" country. This result indicates that contagion occurs mainly within a region, rather than across regions, as it has already been documented in Glick and Rose (1999) and in Kaminsky and Reinhart (2000).

Include Figures 4 to 9 about here

\section{Contagion in Asian countries}

Regarding the Asian flu and its impact in Asia, shift-contagion is also detected. When the Thai Baht devaluation is assumed to be at the origin of the crisis, our analysis provides evidence for contagion from Thailand to Indonesia, Taiwan and the Philippines (figure 8). Alternatively, if we consider that the Asian crisis was triggered by the crash of the Hong Kong stock market, our causality test indicates contagion from Hong Kong to Malaysia, Thailand and the Philippines 
(figure 9). It is interesting to point out that, with the exception of the Philippines, the set of countries contagiously affected by the Asian flu differs whether the ground-zero country is Thailand or Hong Kong. It also appears from figures 8 and 9 that for the set of countries affected by contagion, higher long-run interdependence with the ground-zero country is also detected after the crisis. This result suggests that both shift-contagion and higher interdependence among equity markets contributed to the transmission of the crisis from Hong Kong or Thailand to the other Asian countries. This feature distinguishes the Asian flu from the Tequila crisis, for which shiftcontagion was not associated with higher interdependence.

With respect to spillovers of the Tequila crisis in Asia, it is found that apart from Philippines, the contagion to Asian countries was weak. This result suggests once again that the contagion occurred mainly at a regional level.

\section{Conclusion}

The international financial crises of the last decade have shown that financial shocks in one country can have rapid and large impacts in other countries. This phenomenon revived the literature on contagion, with a surge of papers investigating whether contagion is responsible for this strong linkage among markets during periods of crisis. Measuring financial contagion is not an easy task, because of both conceptual and statistical problems.

The purpose of this paper is to propose a new measure of contagion. We restrict our analysis to contagion defined as a temporary and significant increase in cross-market linkages after a shock. 
Our approach to testing contagion is based on the frequency analysis of causality developed recently by Breitung and Candelon (2004). This approach has two main advantages over existing methods of measuring contagion. First, it provides an elegant way to deal with several of the statistical problems identified in the literature in a unified framework. Second, it permits clearly differentiation between temporary and permanent shifts in cross-market linkages: the first case is contagion, while the second is simply a measure of interdependence among markets.

With this new approach, we test for the existence of contagion among several stock markets in Latin America and Asia during the international financial crises of 1994 and 1997. Our paper provides three main results. While several studies using a time series framework reject the existence of contagion, we find support for contagion during the two crises. In addition, our approach highlights that during the Asian crisis, both contagion and higher interdependence were responsible for the stronger linkages across markets. Such a feature is not observed during the Tequila crisis. Finally, it appears that the spillover effects of these crises have been geographically confined to the region where the shock occurred. This supports the view that contagion is more regional than global, as already suggested by Glick and Rose (1999) and Kaminsky and Reinhart (2000). These three results suggest that causality in the frequency domain is a proper framework for studying contagion. 


\section{References}

[1] Aigner D.J. 1988. Causality, Editor, Special Issue of the Journal of Econometrics. 39 (1-2), $1-234$.

[2] Bae, K.-H., G. Karolyi, and R. Stulz 2000. A New Approach to Measuring Financial Contagion, NBER Working Paper 7913.

[3] Baig, T., Goldfajn, I. 1998. Financial market contagion in the asian crises. IMF Working Paper No. 98/155.

[4] Bayoumi, T., Fazio, G., Kunan, M., McDonald, R. 2003. Fatal attraction: a new measure of contagion. IMF Working Paper 03/80.

[5] Bekaert, G., C. Harvey and A. NG 2003. Market Integration and Contagion, NBER Working Paper 9510.

[6] Breitung, J., Candelon, B. 2004. Testing for Short and Long-run Causality: A Frequency domain Approach. forthcoming in Journal of Econometrics.

[7] Calvo, S., Reinhart, C. 1995. Capital inflows to Latin America: is there evidence of contagion effects? World Bank and International Monetary Fund, Mimeo.

[8] Candelon, B., Hecq, A., Verschoor, W. 2004. Measuring Common Cyclical Features During Financial Turmoil. forthcoming in Journal of International Money and Finance.

[9] Corsetti, G., Pericoli, M., Sbracia, M. 2002. Some contagion, some interdependence, more pitfalls in tests of financial contagion. Working Paper Research Department Bank of 
Italy.

[10] Dufour J.M. And E. Renault (1998), "Short Run and Long Run Causality in Time Series: Theory", Econometrica, 66, 1099-1125.

[11] Dufour J.M. And E. Renault (2003), "Short-run and long-run causality in time series: Inference", Mimeo UQAM, presented at the (EC)2 Conference on Causality, Louvain-la-Neuve, December 2001.

[12] Favero, C., Giavazzi, F 2002. Is the International Propagation of Financial shocks nonlinear? Evidence from the ERM. Journal of International Economics, 57(1), 231-246.

[13] Forbes, K.J., Rigobon, R. 2001. Measuring Contagion: Conceptual and Empirical Issues. In: Claessens, S. and K. Forbes (Eds.), International Financial Contagion, Kluwer Academic Publishers.

[14] Forbes, K.J., Rigobon, R. 2002. No contagion, only interdependence: measuring stock market co-movements. Journal of Finance 57(5), 2223-2261.

[15] Forbes, K. And R. Rigobon 2000. Contagion in Latin America : Definitions, Measurement, and Policy Implications, NBER Working Paper 7885.

[16] Geweke J. 1982. Measurement of Linear Dependence and Feedback Between Multiple Time Series. Journal of the American Statistical Association 77, 304-324.

[17] Glick, R., Rose, A.K. 1999. Contagion and crisis. Why are currency crises regional?. Journal of International Money and Finance 18, 603-617. 
[18] Hotta, L.K., and R.S. Tsay 1998. Outliers in GARCH Process, Unpublished Manuscript.

[19] Kaminsky, G. And C. Reinhart 2000. On crises, contagion, and confusion. Journal of International Economics 51, 145-168.

[20] Kaminsky, G. And C. Reinhart 2001. Financial Markets In Times of Stress, NBER Working Paper 8569.

[21] King, M.,Wadhwani, S. 1990. Transmission of volatility between stock markets. Review of Financial Studies 3, 5-33.

[22] Van Rickenghem, C., Weder, B. 2001. Source of contagion. Is it finance or trade?. Journal of International Economics 54, 293-308.

[23] YaO, F. AND Y. Hosoya 1998.Inference on One-Way Effect and Evidence in Japanese Macroeconomic Data. Journal of Econometrics 98, 225-255. 
Table 1: Empirical Size analysis

\begin{tabular}{|c|c|c|c|}
\hline \hline & $\omega$ & $t=500$ & $t=1.000$ \\
\hline Outlier at $t / 2$ & $3 \pi / 4$ & 0.040 & 0.047 \\
& $\pi / 2$ & 0.047 & 0.046 \\
& $\pi / 4$ & 0.053 & 0.048 \\
\hline Outliers & $3 \pi / 4$ & 0.031 & 0.033 \\
& $\pi / 2$ & 0.039 & 0.040 \\
& $\pi / 4$ & 0.047 & 0.048 \\
\hline GARCH $(0.01,0.2,0.79)$ & $3 \pi / 4$ & 0.060 & 0.057 \\
& $\pi / 2$ & 0.066 & 0.065 \\
& $\pi / 4$ & 0.064 & 0.062 \\
\hline \hline
\end{tabular}

Note: Rejection frequencies of 5,000 Monte Carlo replications based on the previous model. The 0.05 significance level is used. 
Figure 3: Empirical power

$$
\omega=\pi / 4
$$

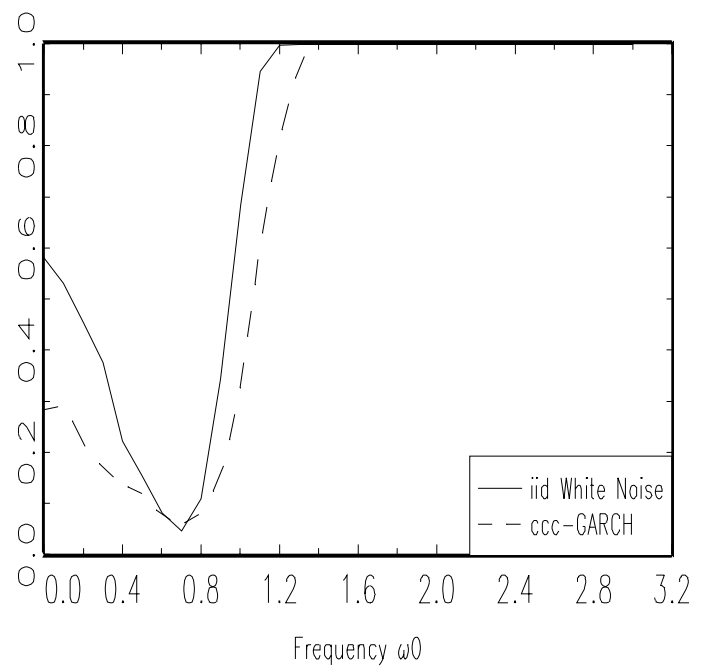

$\omega=\pi / 2$

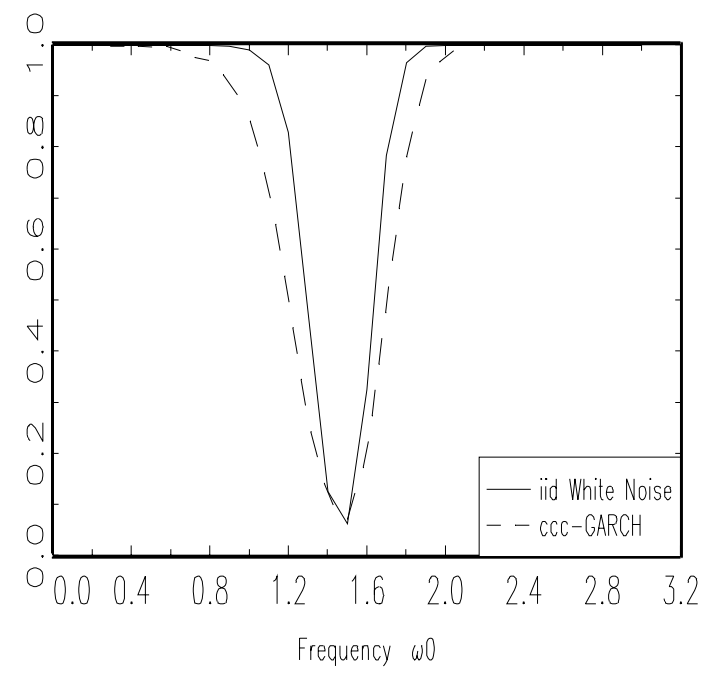


Table 2: Optimal Lag length

\begin{tabular}{ccccccc}
\hline & \multicolumn{2}{l}{ Tequila crisis } & \multicolumn{2}{l}{ Asian Flu } & \multicolumn{2}{l}{ Asian Flu } \\
\hline & $\begin{array}{l}\text { Mexico } \\
\text { zero }\end{array}$ & ground- & \multicolumn{2}{l}{$\begin{array}{l}\text { Thailand } \\
\text { ground-zero }\end{array}$} & $\begin{array}{l}\text { Hong-Kong } \\
\text { ground-zero }\end{array}$ \\
\hline & pre-crisis & post-crisis & Pre-crisis & post-crisis & pre-crisis & post-crisis \\
\hline \hline Argentina & 14 & 8 & 17 & 7 & 20 & 6 \\
Brazil & 11 & 7 & 17 & 4 & 16 & 4 \\
Chile & 13 & 9 & 16 & 9 & 14 & 6 \\
Venezuela & 13 & 3 & 18 & 3 & 20 & 3 \\
Mexico & - & - & 15 & 3 & 20 & 4 \\
\hline Indonesia & 11 & 5 & 17 & 2 & 17 & 4 \\
Korea & 16 & 10 & 16 & 2 & 13 & 8 \\
Malaysia & 13 & 13 & 16 & 2 & 29 & 4 \\
Philippines & 13 & 7 & 16 & 4 & 21 & 4 \\
Taiwan & 13 & 4 & 18 & 4 & 22 & 9 \\
Hong-Kong & 14 & 16 & 17 & 4 & - & - \\
Thailand & 13 & 19 & - & - & 20 & 5 \\
\hline
\end{tabular}

Note: Lag length have been selected using the Akaike information criterion (AIC). For The tequila crisis, the pre-crisis period is $1 / 01 / 1993-16 / 12 / 1994$ and the post-crisis period 2/01/1995 - 29/12/1995. For the Asian flu, if Thailand is considered as the ground-zero country, the pre-crisis period is 1/01/1996 $02 / 07 / 1997$ and the post-crisis period is $28 / 07 / 1997-31 / 12 / 1998$. If Hong-Kong is the ground-zero country, the pre-crisis period is $1 / 01 / 1996-16 / 10 / 1997$ and the post-crisis period is $03 / 11 / 1997-$ $31 / 12 / 1998$ 
Figure 4: Causality in Latin America (Mexico as "ground-zero" country)
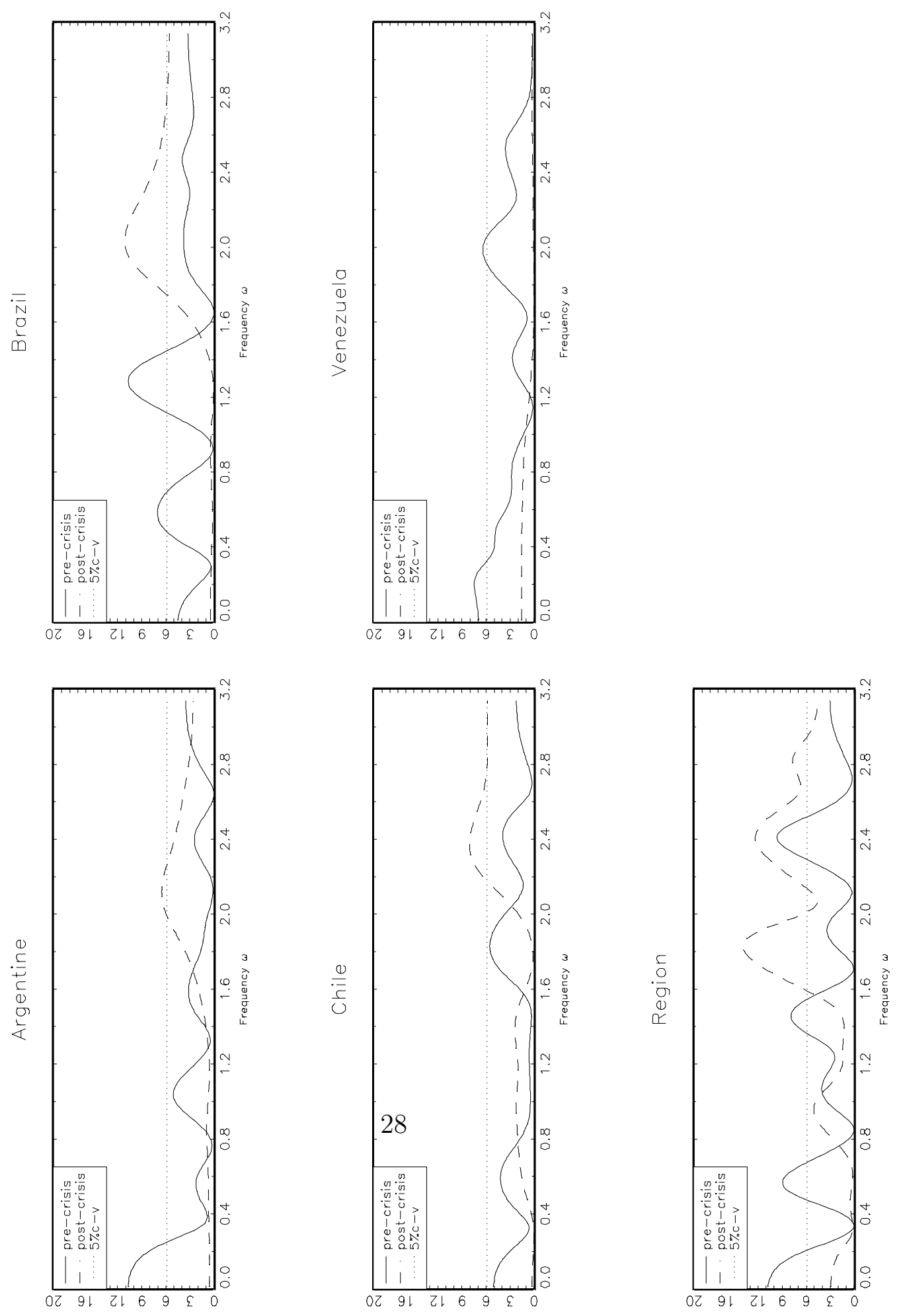
Figure 5: Causality in Latin America (Thailand as "ground-zero" country)
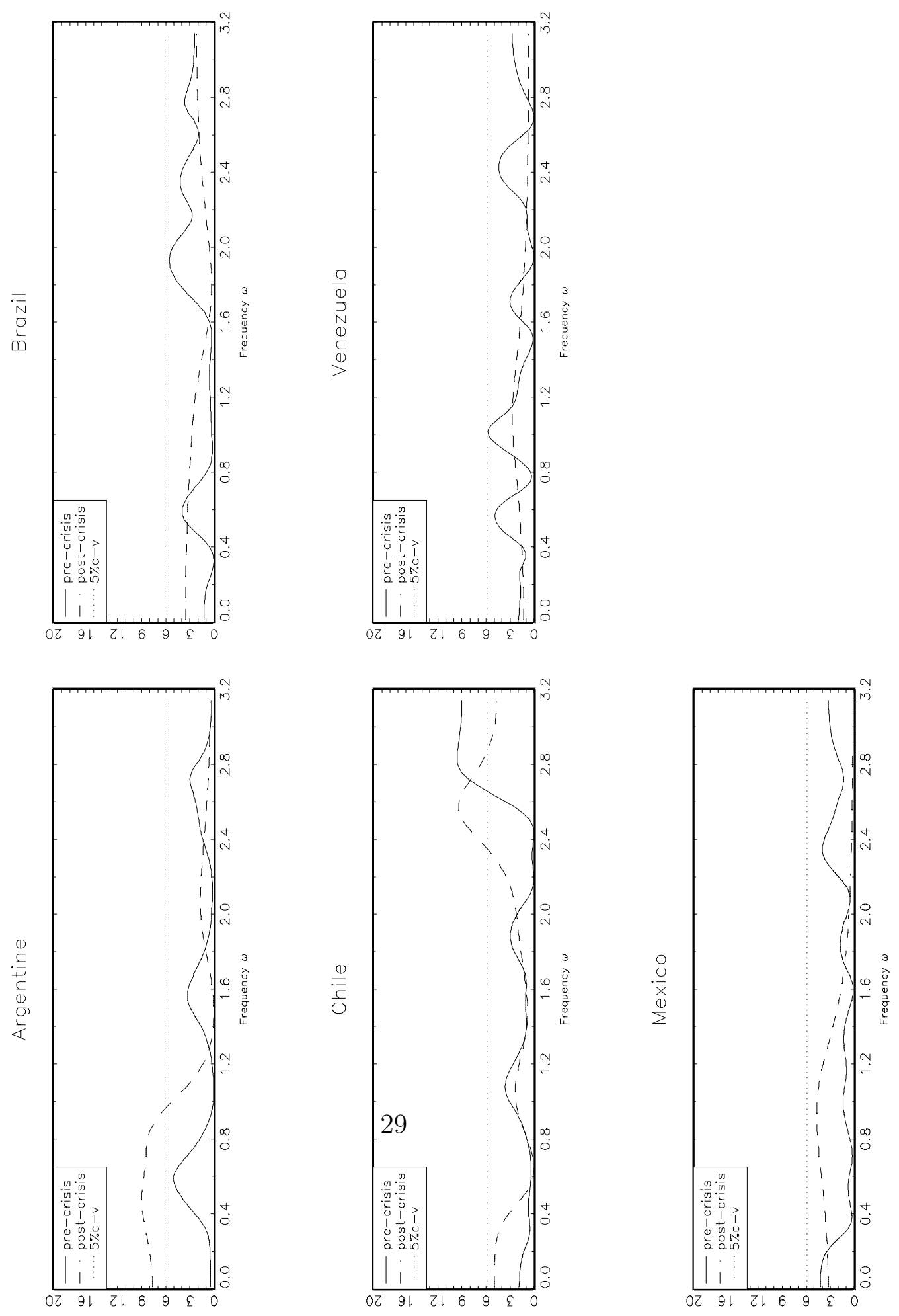
Figure 6: Causality in Latin America (Hong-Kong as "ground-zero" country)
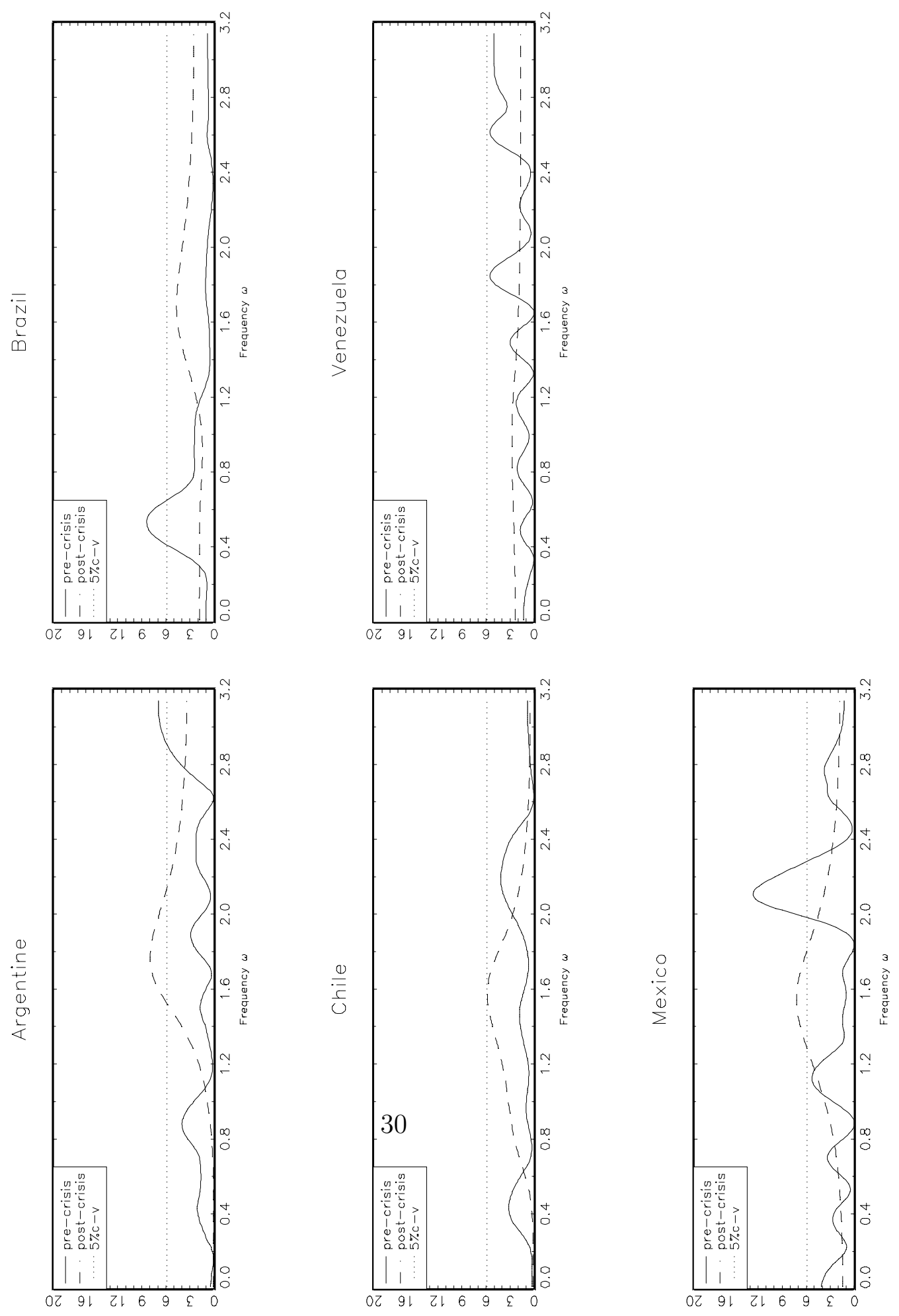
Figure 7: Causality in Asia (Mexico as "ground-zero" country)
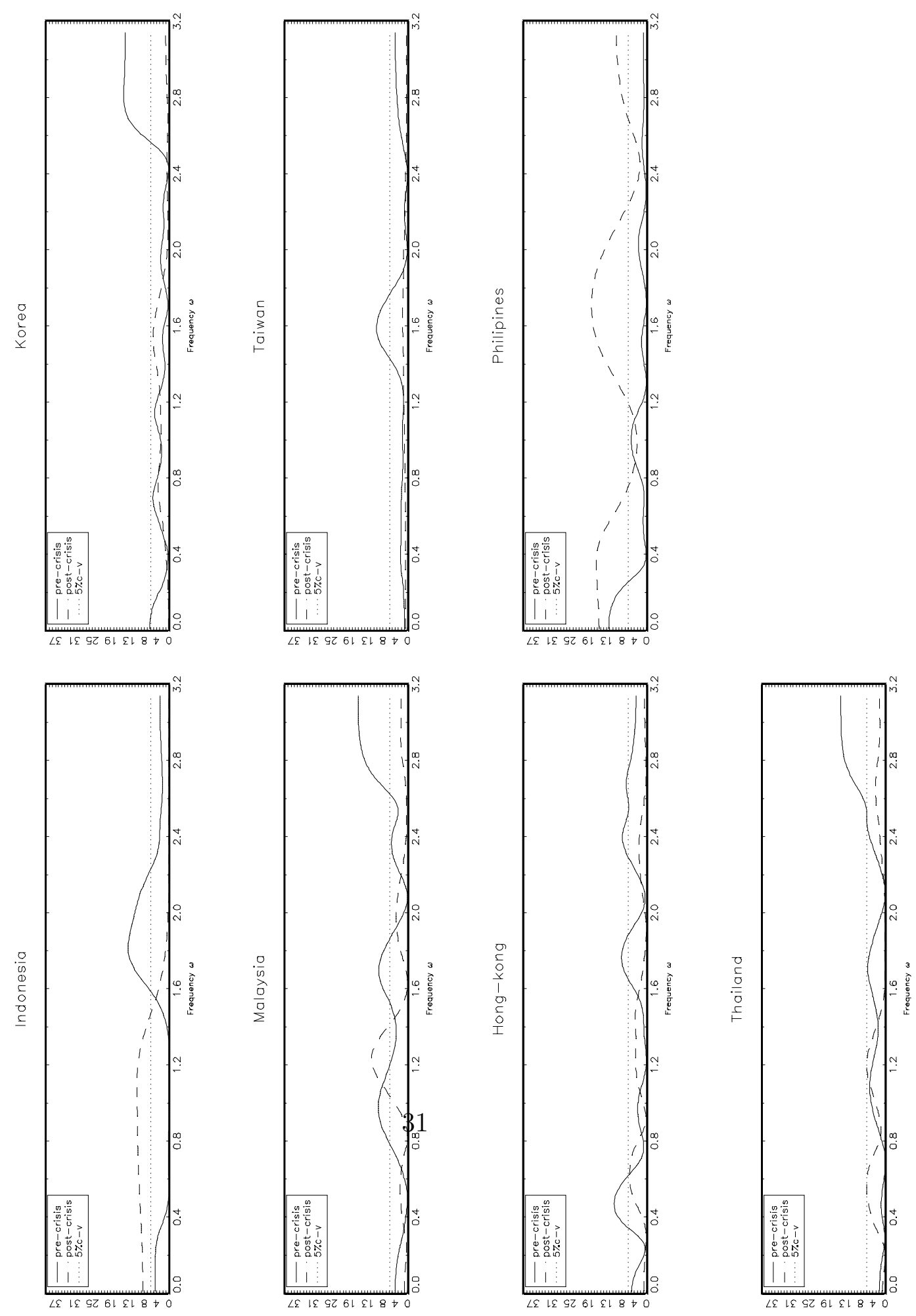
Figure 8: Causality in Asia (Thailand as "ground-zero" country)
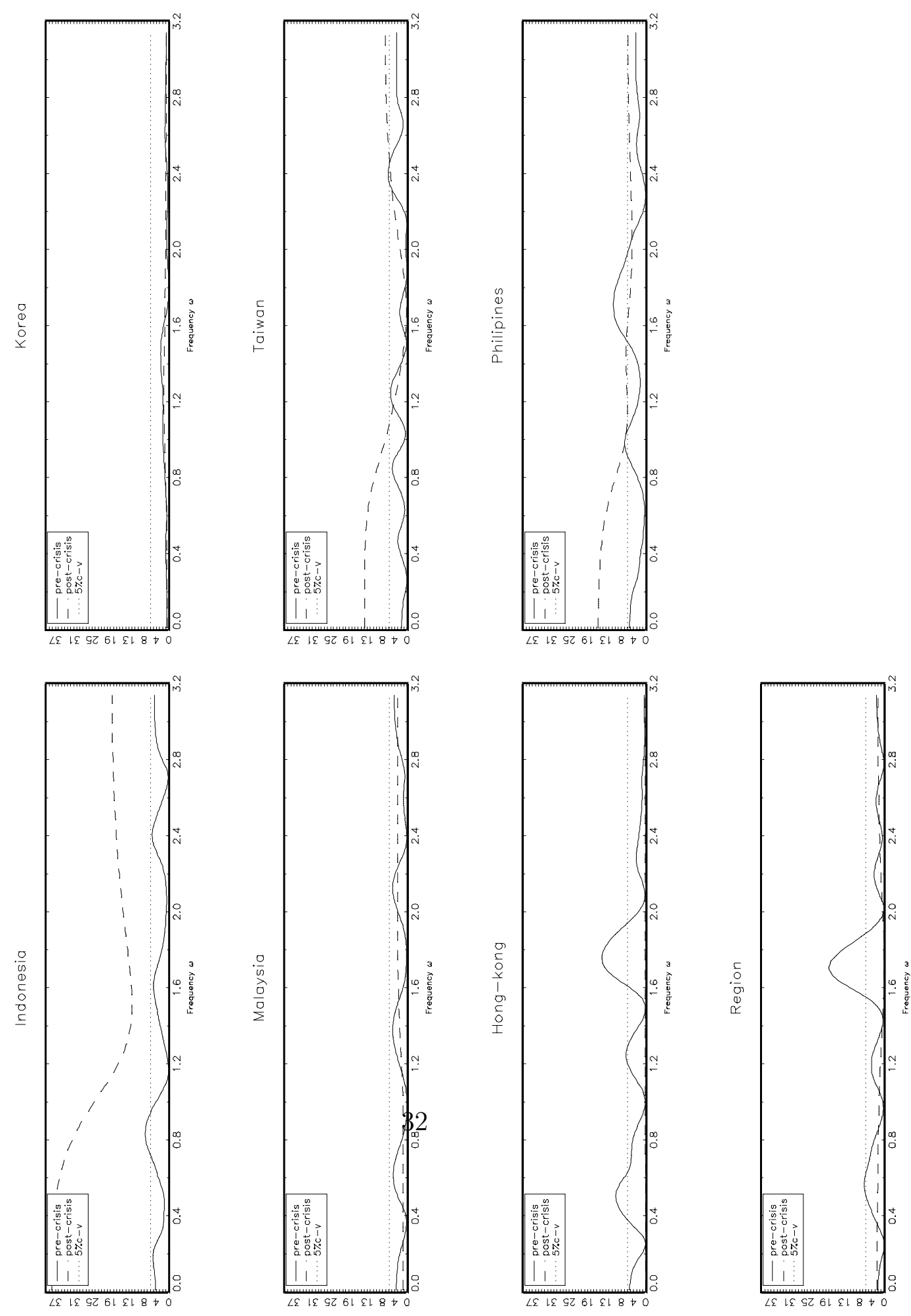
Figure 9: Causality in Asia (Hong-Kong as "ground-zero" country)
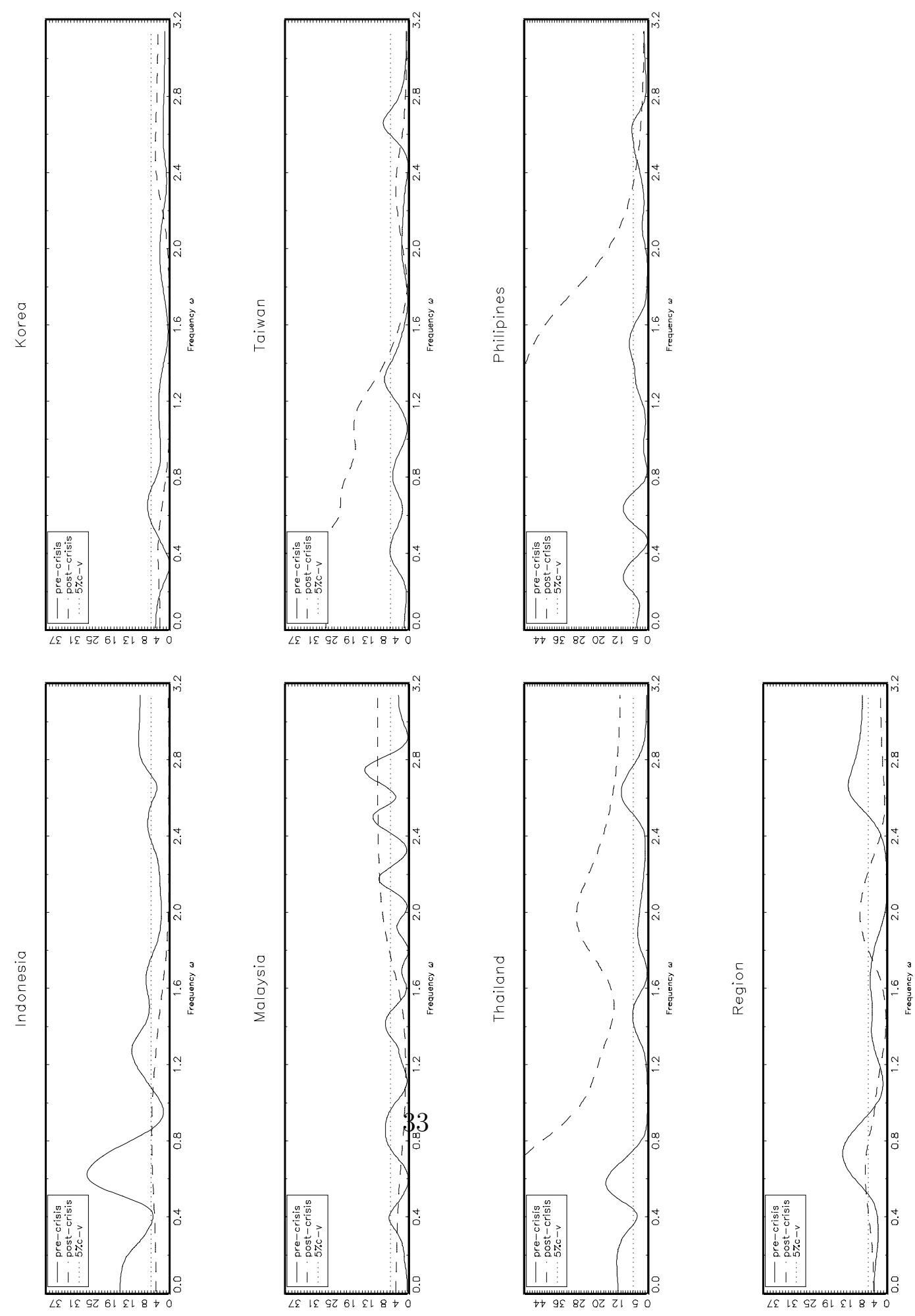


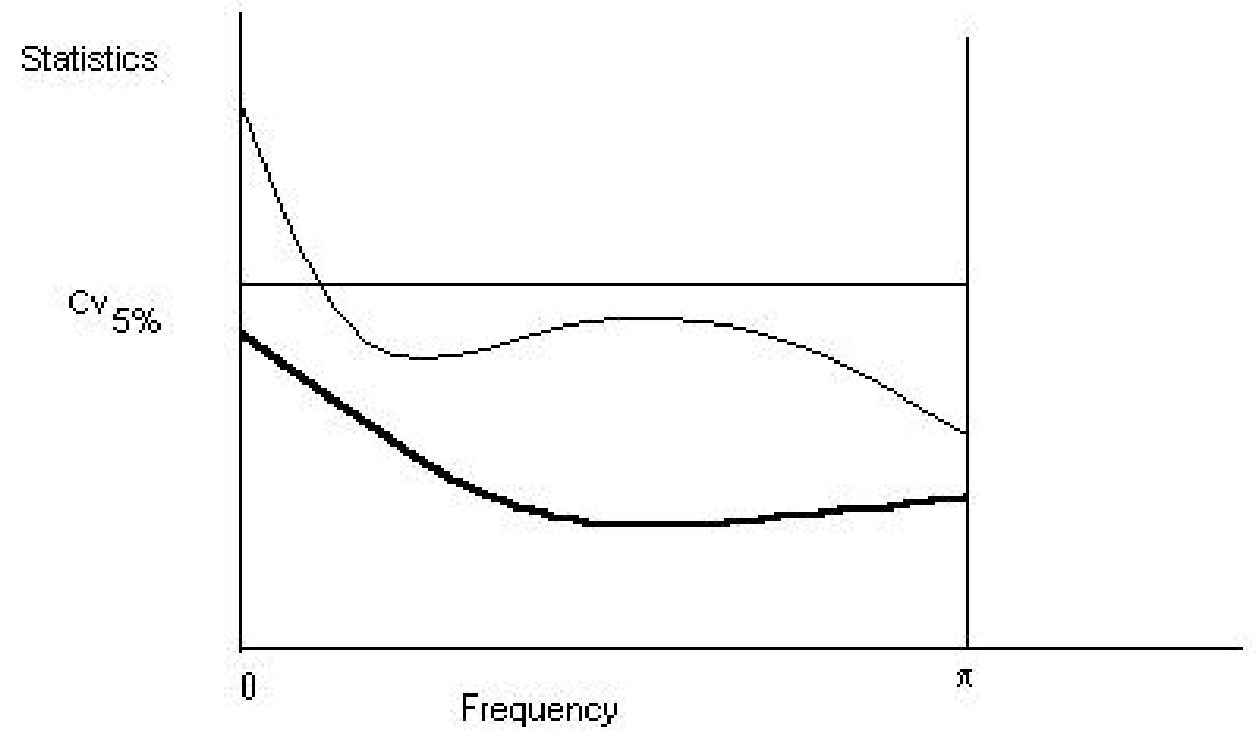

Figure 1: Causality test with long-run dependence

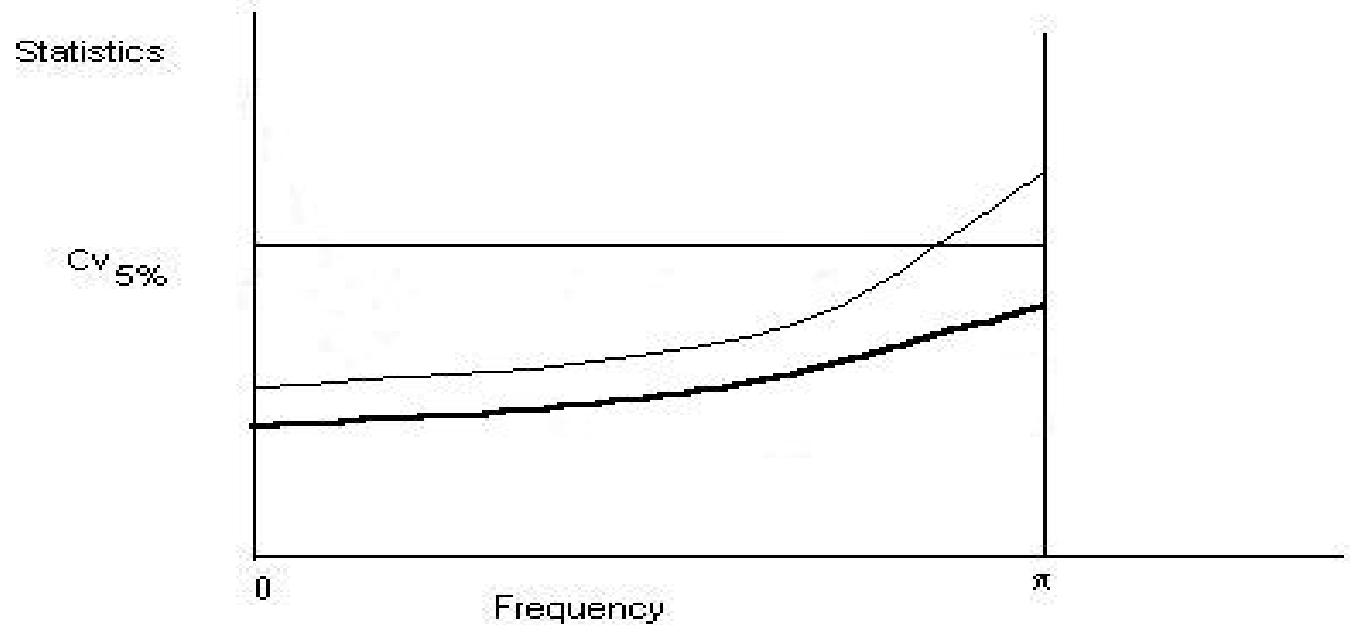

Figure 2: Causality test with contagion 